\title{
Intron retention generates ANKRD1 splice variants that are co-regulated with the main transcript in normal and failing myocardium
}

\author{
Mario Torrado ${ }^{\mathrm{a}}$, Raquel Iglesias ${ }^{\mathrm{a}}$, Beatriz Nespereira ${ }^{\mathrm{a}}$, Alberto Centeno ${ }^{\mathrm{b}}$, Eduardo \\ López $^{\mathrm{b}}$, Alexander T. Mikhailov ${ }^{\mathrm{a}}$ \\ ${ }^{a}$ Developmental Biology Group, Institute of Health Sciences, University of La Coruña, As Xubias s/n, 15006 \\ La Coruña, Spain \\ ${ }^{b}$ Experimental Surgery Unit, University Hospital Center of La Coruña, Xubias de Arriba 84, 15006 La \\ Coruña, Spain
}

\begin{abstract}
The cardiac ankyrin repeat domain 1 protein (ANKRD1, also known as CARP) has been extensively characterized with regard to its proposed functions as a cardio-enriched transcriptional co-factor and stressinducible myofibrillar protein. The present results show the occurrence of alternative splicing by intron retention events in the pig and human ankrdl gene. In pig heart, ankrdl is expressed as four alternatively spliced transcripts, three of which have non-excised introns: ankrdl-contained introns 6, 7 and 8 (i.e., ankrdli6,7,8), ankrdl-contained introns 7 and 8 (i.e., ankrdl-i7,8), and ankrdl retained only intron 8 (i.e., ankrdli8). In the human heart, two orthologues of porcine intron-retaining ankrdl variants (i.e., ankrdl-i8 and ankrd1-i7,8) are detected. We demonstrate that these newly-identified intron-retaining ankrdl transcripts are functionally intact, efficiently translated into protein in vitro and exported to the cytoplasm in cardiomyocytes in vivo. In the piglet heart, both the intronless and intron-retaining ankrd1 mRNAs are co-expressed in a chamber-dependent manner being more abundant in the left as compared to the right myocardium. Our data further indicate co-upregulation of the ankrdl spliced variants in myocardium in the porcine model of diastolic heart failure. Most significantly, we demonstrate that in vivo forced expression of recombinant intronless ankrdl markedly increases the levels of intron-retaining ankrdl variants (but not of the endogenous main transcript) in piglet myocardium, suggesting that ANKRD1 may positively regulate the expression of its own intron-containing RNAs in response to cardiac stress. Overall, our findings demonstrate that in cardiomyocytes ANKRD1 can exist in multiple isoforms which may contribute to the functional diversity of this factor in heart development and disease.
\end{abstract}

\begin{abstract}
Abbreviations
ANKRD1, ankyrin repeat domain 1 protein; MARPs, muscle ankyrin repeat proteins; SRF, serum response factor; HF, heart failure; DHF, diastolic HF; LV/RV, left/right ventricular myocardium; LA/RA, left/right atrial myocardium; FW, free wall; ESP, end-systolic pressure; EDP, end-diastolic pressure; RT, room temperature; RT-PCR-DD, reverse transcription-PCR differential display; PAAG, polyacrylamide gel; RACE, rapid amplification of cDNA ends; RPL19, ribosomal protein L19; GAPDH, glyceraldehyde 3phosphate dehydrogenase; RT-PCR, reverse transcription-polymerase chain reaction; IVTT, in vitro transcription/translation system; qPCR, real-time quantitative RT-PCR; FBS, fetal bovine serum; MW, molecular weight; TC, termination/stop codon; PTC, premature termination codon; NMD, nonsense-mediated mRNA decay
\end{abstract}

Keywords

ANKRD1/CARP; Alternative splicing; Intron retention; Myocardium; Gene delivery; Heart failure 


\section{Introduction}

The ankyrin repeat domain 1 protein (ANKRD1, also known as CARP) is a member of a small protein family of muscle ankyrin repeat proteins (MARPs) that consist of ANKRD1, a proline-rich ankyrin repeat protein (ANKRD2/ARPP), and diabetes related ankyrin repeat polypeptide (ANKRD23/DARP). All members are characterized by the presence of four ankyrin repeats in their C-termini, the capacity to interact with the elastic filamentous protein titin and similar intracellular distribution in both cardiac and skeletal muscle fibers. Among the MARP family, cardiac-enriched ANKRD1 has been the one most extensively characterized with regard to its proposed functions as a transcriptional co-factor and stress-inducible myofibrillar protein, reviewed in Granzier and Labeit (2004), Miller et al. (2004), and Mikhailov and Torrado (2008).

Initially, ANKRD1 was identified as a regulatory factor named as C-193 (Chu et al., 1995) involved in the cytokine-induced activation of microvascular endothelial cells. Further independent studies led to the discovery of an identical factor as a cardiac (Zou et al., 1997) and muscle (Baumeister et al., 1997) ankyrin repeat protein (named, respectively, as CARP and MARP) or as a cardiac andriamycin-response protein named as CARP (Jeyaseelan et al., 1997) or CRAP (Hiroi et al., 2001). This has led to the confusing gene nomenclature, with several different or duplicated names having been given to the same gene/protein. Recently, the unique gene symbol, ankrdl, has been approved by the HUGO Gene Nomenclature Committee.

The ankrdl gene is highly conserved among the mammals studied up to date and is structured in 9 exons and the respective 8 introns. The primary transcript is processed to encode a protein product with an apparent molecular size of 39-40 kDa (Zou et al., 1997; Torrado et al., 2004, 2006). The degradation motif in the $3^{\prime}$ untranslated region of the ankrdl mRNA, as well as the potential PEST-like degradation sequence and putative phosphorylation and glycosylation sites suggest that the endogenous expression of ankrdl can be regulated at both post-transcriptional and post-translational levels (Samaras et al., 2007; Witt et al., 2008). Only one ankrdl transcript was reported in mammals studied up to date. The ankrdl gene is located on chromosome 10 in humans, 14 in pigs (Dong et al., 2007) and 19 in mice.

The ankrdl gene, a downstream target of $N k x 2.5$, Gata-4, SRF and $S p 3$ transcription factors, is constitutively expressed in fetal, neonatal and adult myocardium. Distinct $5^{\prime}$ cis regulatory elements of the ankrdl gene can direct chamber-dependent gene expression, such as atrial versus ventricular and left versus right (Kuo et al., 1999). In this regard, left-right asymmetric patterns of ankrdl cardiac expression are most obvious in newborn and early-postnatal pigs (Torrado et al., 2004, 2006).

ANKRD1 was thought to be involved in the regulation of cardiac gene expression during fetal heart development via its interaction with transcription factor YB-1 (Zou et al., 1997). Later, ankrdl has been characterized as an inducible gene that is over-expressed in fetal, early-postnatal and adult heart in response to multiple forms of cardiovascular stress, including pressure overload, chronic ischemia, infarction-reperfusion injury and at heart failure (HF) (Mikhailov and Torrado, 2008).

Although the functions of ankrdl in the myocardium are still poorly delineated, several recent reports emphasize the role of ankrdl in the protection of cardiac (Han et al., 2005) and microvascular endothelial (Samaras et al., 2007) cells against apoptosis and this gene's involvement in the adaptive response of ventricular myocardium to pressure overload (Mikhailov and Torrado, 2008). In addition, ankrdl has also been identified as a candidate gene that can play an important role in congenital cardiac (Cinquetti et al., 2008) and skeletal muscle (Bakay et al., 2002; Nakada et al., 2003) disease, as well as in angiogenesis (Boengler et al., 2003), neovascularization (Shi et al., 2005; Samaras et al., 2007) and neurite outgrowth (Stam et al., 2007). In in vivo experimental settings, ANKRD1 is used as a surrogate biomarker of cardiac hypertrophy (Aihara et al., 2000), cardio-toxic damage (Torrado et al., 2004) or skeletal myopathy (Casey et al., 2008). 
The robust increase in ankrdl expression after various physiological stimuli or pathological insults suggests the gene appears to be involved in responding to muscle-specific stresses, such as biomechanical stretch, hypertrophic remodeling and sarcomeric dysfunction (Miller et al., 2003; Blais et al., 2005). Although a high stress-induced level of the ankrdl mRNA results from a rapid burst of gene transcription (Kanai et al., 2001), it is increasingly more recognized that posttranscriptional regulation can also be an important mechanism in terms of controlling ankrdl transcript and protein abundance (Zolk et al., 2003; Samaras et al., 2007; Witt et al., 2008).

Intron retention is a potential component of post-transcriptional regulation of gene expression in response to various conditions of stress (Nurmi et al., 2005; Bowman et al., 2006; Yoshida et al., 2006; Fernandes et al., 2007). It is well-documented that the presence of an intron in a given transcript can enhance both gene expression (Korb et al., 1993; Le Hir et al., 2003; Nott et al., 2003; De Jaco et al., 2005) and mRNA stability (Wang et al., 2007; Zhao and Hamilton, 2007). In mammals, however, no study has yet addressed the alternative splicing events in the processing of the primary intron-containing ankrdl transcript and no spliced ankrdl variants have been reported.

We provide here the results on the identification of previously unrecognized splice ankrdl variants, each characterized by the retention of different introns in the final version of the different ankrdl mRNAs expressed in normal neonatal and adult myocardium in pigs and humans. Porcine ankrdl splice variants are stable transcripts which are positively co-regulated (with the main transcript) in the left versus right ventricular (LV versus RV) myocardium during postnatal development and at experimental HF. Together, these data indicate that ankrdl splice variants are associated with both physiological and pathological remodeling of mammalian myocardium. More broadly, our findings demonstrate that ANKRD1 can exist in multiple isoforms within cardiomyocytes which might contribute to the functional diversity of this factor in heart development and disease.

\section{Materials and methods}

\subsection{Porcine model of heart failure}

A low-output-type diastolic heart failure (DHF) model was established in 6-day-old neonatal piglets by i.v. injection of cardio-toxic agent, Doxorubicin (Dox) as described (Torrado et al., 2006). Briefly, piglets $(n=12)$ exposed to Dox (Sigma) at a dose of $1.5 \mathrm{mg} / \mathrm{kg}$ developed a severe diastolic dysfunction with pulmonary congestion, leading to DHF with low premature mortality before the planned end of the study. Animals $(n=12)$ injected with normal isotonic saline (PBS) were used as controls. On day 24 after injection, cardiac output and extravascular lung water were monitored in close-chest piglets by PiCCO device (Pulsion AG, Germany) in accordance with the manufacturer's recommendations. The measurements of ventricular end-systolic (ESP) and enddiastolic pressure (EDP) were performed in open-chest piglets using a Dräger UM3.1 pressure transducer and a recording device (Drägerwerk AG, Germany) as described in Torrado et al. (2006). Then piglets were euthanized to harvest cardiac tissues for RNA and protein isolation. Myocardial samples were also isolated from newborn piglets. Piglets were used in accordance with protocols approved by the Institutional Animal Care and Use Ethical Committee.

\subsection{Targeted myocardial gene delivery in vivo}

The expression plasmid, encoding a FLAG-tagged intronless coding sequence of the porcine ankrd1 (GenBank accession number: NM_213922), in p3XFLAG-CMV-14 vector (Sigma) driven by a human cytomegalovirus (CMV) promoter/enhancer was used. The ankrdl constructs were verified by sequencing. Plasmids grown in XL1-Blue Supercompetent E. coli cells (Stratagene) were purified by using a PureLink HiPure plasmid filter purification kit (Invitrogen) according to the manufacturer's protocol. Plasmids were formulated at a final DNA concentration of $1 \mathrm{mg} / \mathrm{ml}$ in sterile isotonic saline (PBS). Neonatal 6-day-old piglets were randomized in three groups and assigned to receive intramyocardial injections of: (1) ankrdl plasmid DNA $(n=8)$, (2) vector alone plasmid $(n=4)$, and (3) PBS $(n=4)$. While under anesthesia and mechanical ventilatory support, a fiber-optic catheter (Cardio-Optics Inc.) and endoscopic tubular ( $3 \mathrm{~mm})$ cannula were 
introduced into left chest cavity as described (Torrado et al., 2008). Then, the endoscopic needle was introduced into the cannula, and intramyocardial injections were performed in the ventrolateral area of the LVFW under direct visualization. On the 2nd day after gene transfer, the measurements of VESP and VEDP were performed in open-chest piglets as described just above. Then animals were euthanized and the hearts were rapidly excised, weighed, and photographed. The ventral LVFW of each heart was sectioned into 9 regions $(\sim 1 \times 1 \mathrm{~cm}$ each; see Fig. 6$)$ which were then assayed individually for RNA and protein isolation, and tissue fixation (Torrado et al., 2008).

\subsection{Human myocardial samples}

Samples (100-300 mg) encompassing the full thickness of the free wall of the left and right ventricles, were obtained from five adult donor hearts (20-56 years old) not transplanted for technical reasons, according to the University Hospital Center (La Coruña, Spain) guidelines for confidentiality and privacy. Cardiac specimens were also collected postoperatively from two infant patients (8-week- and 12-month-old) with septal defects who died during general anesthesia procedure. Samples were collected into RNAlatter solution (Ambion) and stored at $-80{ }^{\circ} \mathrm{C}$ until being analyzed. Informed consent was obtained from patient relatives, and the protocol was approved by the respective Institutional Ethics Committee. The investigation adheres to the principles outlined in the Declaration of Helsinki.

\subsection{RNA isolation}

For total RNA isolation, deep-frozen cardiac-tissue samples were directly disrupted in RLT buffer (Qiagen) using a high-speed rotor-stator homogenizer (Ultra-Turrax T8, Germany), digested with Proteinase K (Oiagen), loaded into an RNeasy Midi column (Qiagen), subjected to two rounds of on-column digestion of DNA with RNase-free DNase (Qiagen), and processed in accordance with the manufacturer's recommendations. For cytoplasmic RNA isolation, LV tissue dissociation was performed by serial digestion with collagenase (Sigma) and trypsin (Sigma), as described for neonatal hearts (Osinska and Lemanski, 1993). Resulting cardiomyocyte suspension was sedimented ( $200 \mathrm{~g}$ for $3 \mathrm{~min}$ at RT), and cytoplasmic RNA was purified with a commercially available RNA isolation kit (RNeasy Mini Kit; Qiagen) using a protocol designed for isolation of cytoplasmic RNA. Total RNA was also isolated from separate batches of cardiomyocyte suspension as described above. Resulting RNA preparations were ethanol-precipitated, resolved in RNase-free $\mathrm{H}_{2} \mathrm{O}$, and kept at $-80^{\circ} \mathrm{C}$. RNA yield and purity was determined spectrophotometrically at $260-280 \mathrm{~nm}$ and RNA integrity was verified by running samples on $1.5 \%$ agarose gels and staining with ethidium bromide.

\subsection{Reverse transcription-PCR differential display (RT-PCR-DD)}

The RT-PCR-DD assay was performed as described (Kokame et al., 1998) with minor modifications. To yield starting material for the RT-PCR-DD, total RNA preparations independently isolated from LV and RV of three newborn piglets were respectively pooled at equal ratios, and $4 \mu \mathrm{g}$ of RNA was reverse transcribed using the SuperScript III (Invitrogen) and T7-oligo-dT primer. Pooled first-strand cDNAs were amplified side-by-side by PCR using 200 different primer combinations (10 two-base-anchored oligo-dT and 20 arbitrary primers purified by HPLC) (Supplementary table 1). PCR products were subject to fractionation on $8 \%$ polyacrylamide gels (PAAG) (Mini-Protean-III, Bio-Rad) and fluorescently stained by SYBR Green I (Sigma). Bands with a differential expression between LV and RV were cut out, electroeluted (D-tube Electroelution Kit, Novagen), re-amplified, cloned into pCRII-TOPO vector (Invitrogen) and sequenced as a service by "Secugen" (Madrid, Spain). For validation of differential expression, real-time quantitative PCR was used (Rajeevan et al., 2001). 
Rapid amplification of cDNA ends (RACE) methods were used to characterize the 5'and 3ends of the alternatively spliced pig ankrdl mRNAs using SMART RACE cDNA amplification kit (Clontech) according to the manufacturer's protocol. Briefly, 5'- and 3'-RACE-ready cDNAs were generated as separate cDNA samples using $1 \mu \mathrm{g}$ of a total RNA isolated from the LV of newborn piglets, PowerScript reverse transcriptase and modified oligonucleotides for incorporation of the SMART sequence into both 5'- and 3'-RACE-ready cDNA populations. Dilutions of each 5'- and 3'-RACE-ready cDNAs were used in PCR amplification reactions with the SMART RACE kit universal primer mix A, pig ankrdl gene-specific primers (see Fig. 1D, forward primers 182, 183 and reverse primer 181) and Advantage 2 Polymerase (Clontech). Amplification products were run on agarose gels, gel-purified, cloned and sequenced. 
primers:

A

A04-H06

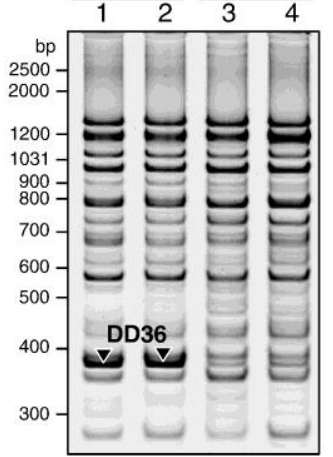

B

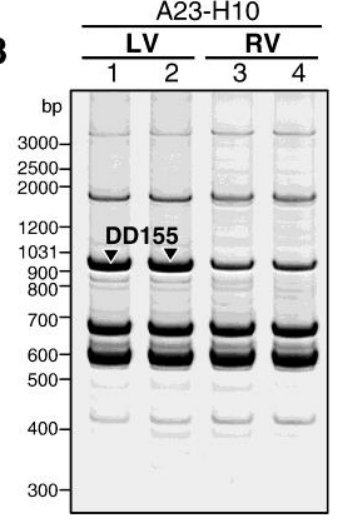

C

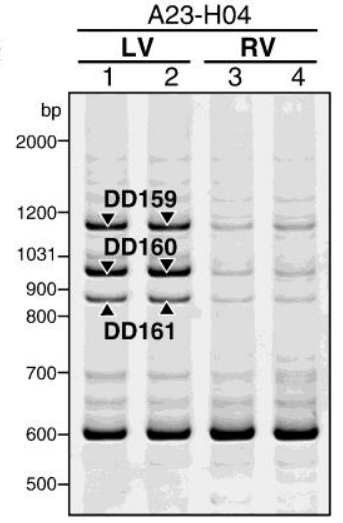

199
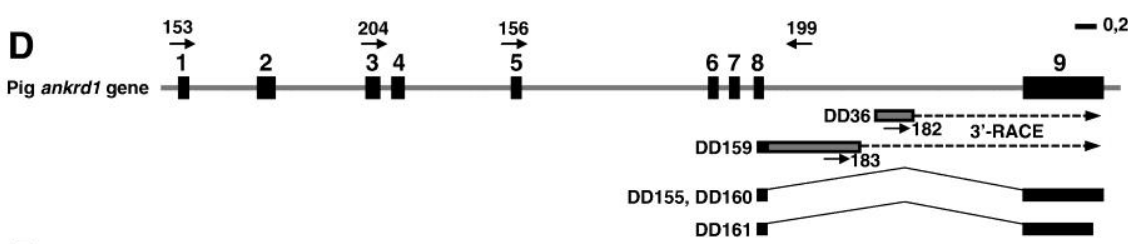

E

primers: $\frac{153-199}{\mathrm{~L}} \frac{\mathrm{RT}+\mathrm{204-199}}{\mathrm{RT}-} \frac{156-199}{\mathrm{RT}-} \frac{\mathrm{RT}+}{\mathrm{RT}-} \frac{\mathrm{RT}+}{\mathrm{n}} \mathrm{n}$

bp

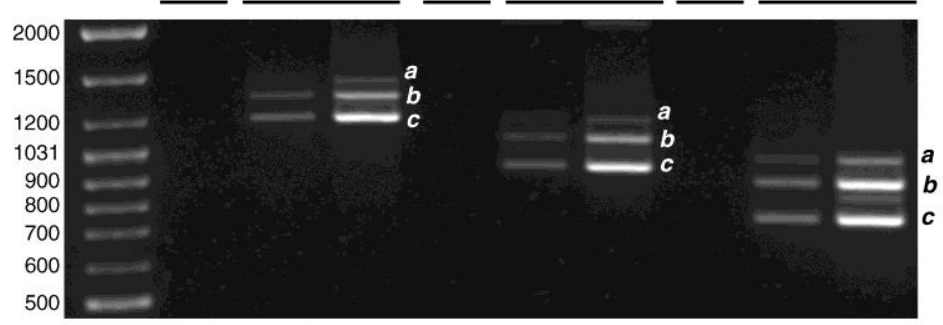

$\mathbf{F}$

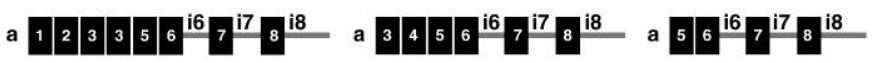

6 1/2/3/45/677

11/2/3/45/6/7/8 i8

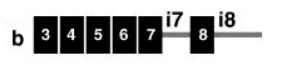

c \begin{tabular}{l|l|l|l|l|l}
3 & 4 & 5 & 6 & 7 & 8 \\
\hline
\end{tabular} b $5 \longdiv { 6 7 7 ^ { 1 7 } } 8$

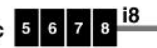

G

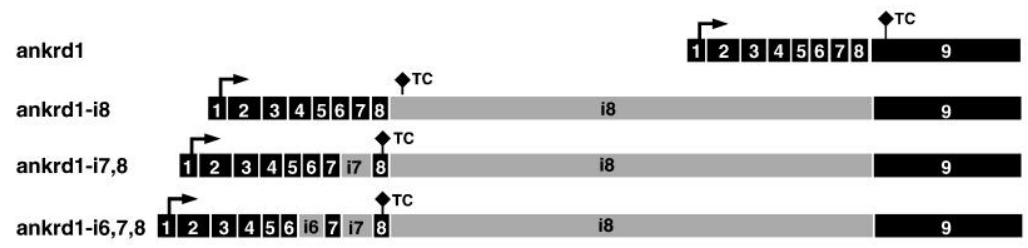

Fig. 1. Identification and characterization of pig ankrdl splice variants generated by intron retention. (A-C) Representative band patterns on RT-PCR-DD analysis showing upregulated PCR fragments in the left (LV) versus right ventricle (RV) of newborn piglets (samples were run in duplicate). Non-denaturing $8 \%$ polyacrylamide gels post-stained with SYBR Green I. Black arrows indicate signals demonstrating LV-predominate expression. (D) Schematic representation of the pig ankrdl gene (GeneID: 396959), DD36 and DD159 fragments, their 3'-RACE PCR products (arrowed dotted-lines), and DD155, DD160 and DD161 fragments (after alignment of the fragment sequences with that of the pig ankrd1 gene). Exons are denoted with numbered black boxes and introns with grey horizontal lines. The approximate location of the primers for downstream PCR analysis (E) is shown. Bar- $0.2 \mathrm{~kb}$. (E) Expression of three splice ankrdl variants (a, b, c) as revealed by PCR from oligo-dT-primed 1st strand cDNA from piglet LV using the indicated sets of primers. Reactions were run in duplicate using 2-fold dilutions of cDNA (RT+). RT-: non-RT control. L-DNA size standards (GeneRuler DNA ladder mix; Fermentas). (F) Schematic representation of structural organization of each of the PCR products generated by retention of: (a) introns 6, 7 and 8, (b) introns 7 and 8, and (c) intron 8. Exons and introns (i) are shaded black and grey, respectively. G-predicted protein structure of normally sized and intron-retaining ankrdl variants. TC — termination/stop codon. 


\subsection{Semiquantitative reverse transcription-polymerase chain reaction (RT-PCR)}

$2 \mu \mathrm{g}$ of RNA were reverse transcribed using SuperScript III reverse transcriptase (Invitrogen) and oligo-dT primer according to the manufacturer's instructions. Piglet cardiac cDNAs were used for PCR reactions in a Biometra II PCR system to detect different RNAs using the primers indicated in Supplementary table 1. Semiquantitative RT-PCR was performed as described previously (Torrado et al., 2003, 2004). Detection of various ankrdl variants was performed using primers located on exon-exon or exon-intron junctions. The amount of cDNA and the number of cycles were varied for each primer pair to ensure amplification within the linear phase. All PCR reactions included primers for the candidate (ankrdl) and reference (rpll9 or gapdh) transcripts. A discriminating primer set (derived from the FLAG vector sequence) was used for specific amplification of in vivo delivered FLAG-tagged ankrdl (see Supplementary table 1). Reactions, including no-RT and no template (NT) controls, were performed at least in triplicate. The PCR products were subcloned and sequenced to confirm their identity. PCR products were visualized on $2 \%$ agarose gels by ethidium bromide staining and band intensity was estimated by densitometry (VersaDoc 1000) and Quantity One software (Bio-Rad).

\subsection{Real-time quantitative RT-PCR ( $q P C R)$}

Two-step qPCR was performed on a Bio-Rad IQ5 detection system with SYBR Green mix (Torrado et al., 2006). Within each experiment, PCR reactions were done in duplicate. For each RNA sample, genomic DNA contamination was determined by PCR on a no-RT control for the housekeeping gene rpl19. Cycling parameters used were standard for SYBR Green analysis. Results were normalized against rpl19 expression. The efficiency of target and reference amplification was tested to be approximately equal. Each primer pair used yielded a single peak of dissociation on the melting curve and a single band with the expected size on SYBR Green-stained PAAG (see Fig 4G). Repeated qPCR analysis of a given RNA sample, i.e., technical replicates, yielded variations of less than $5 \%$. Fold changes were calculated using the $\mathrm{C}_{\mathrm{T}}$ method. $\mathrm{C}_{\mathrm{T}}$ values for individual ankrdl variants were compared to $\mathrm{C}_{\mathrm{T}}$ values for a reference control (rpl19) for all cardiac samples. For primer sequences used in qPCR analysis see Supplementary table 1.

\subsection{Gene cloning and cell-free expression in vitro}

Coding sequences of the intronless and intron-retaining variants of pig ankrdl were amplified from piglet LV oligo-dT primed cDNA, cloned into T7 promoter-containing vector pcDNA3.1/myc-His B (Invitrogen), verified by sequencing and expressed in vitro using TnT T7 Quick Coupled in vitro Transcription/Translation (IVTT) System (Promega) in the presence or absence of $\left[{ }^{35} \mathrm{~S}\right]$-labeled methionine as described (Torrado et al., 2005). The corresponding protein products were purified on Sephadex G-50 columns (Amersham Bioscience) and used in downstream SDS-PAGE and Western-blot experiments.

\subsection{Cell culture, transfection and transient expression assays}

COS-7 cells were cultured in D-MEM (Gibco) supplemented with $10 \%$ fetal bovine serum (FBS), penicillin-streptomycin-glutamine (Gibco) under standard tissue culture conditions at $37^{\circ} \mathrm{C}$. Cells were trypsinized at 70-80\% confluence, and 140,000 cells were plated in each well of 12 -well plates and allowed to attach overnight. Transfection of each CMV-driven-ankrdlexpressing plasmid (see Fig 2A) or empty vector was carried out with FuGENE HD transfection reagent (Roche) following the manufacturer's instructions. A total of $1.0 \mu \mathrm{g}$ of each plasmid DNA was used to transfect cells cultured in 12 -well dishes to $80 \%$ confluence. Sterile polystyrene well plates were used to form transfection complexes at DNA:transfection reagent ratio 1:3. After 24hour incubation, the medium was removed, the cells were scraped into $200 \mu 12 \times$ Laemmli sample buffer (Invitrogen), and cell extracts were collected for Western blot analysis. For each plasmid, at least three separate transfection assays were employed, and at each assay, transfections were performed in triplicate. 
A

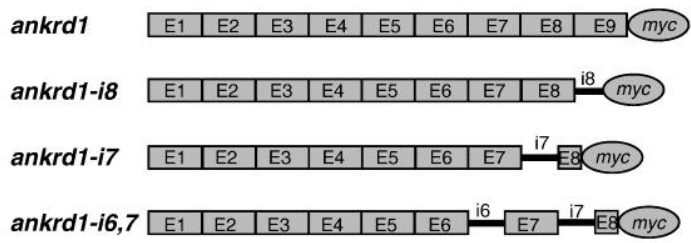

B

WB: anti-myc

$\begin{array}{lllll}1 & 2 & 3 & 4 & 5\end{array}$

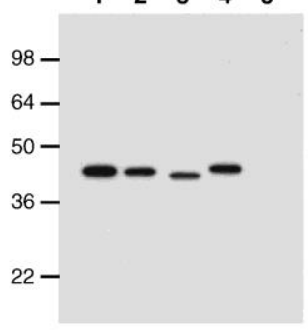

WB: anti-myc

C

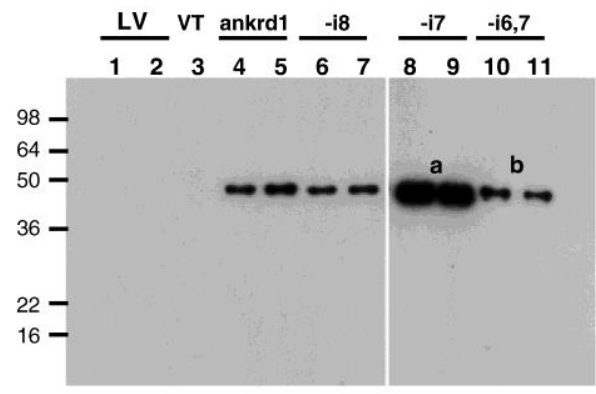

D

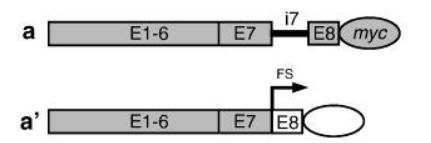

anti-ANKRD1

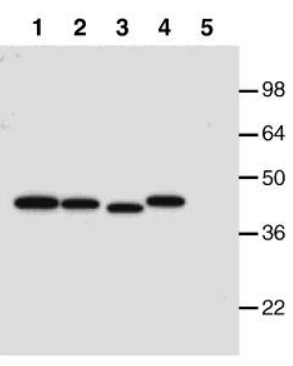

WB: anti-ANKRD1

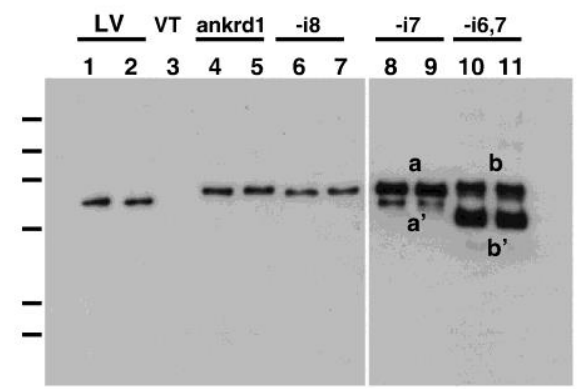

b \begin{tabular}{|l|l|l|l|l|}
\hline E1-5 & E6 \\
\hline
\end{tabular}

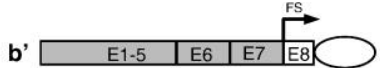

Fig. 2. Expression of the intronless and intron-bearing ankrdl constructs in cell-free (IVTT) and cell-based (COS-7) expression assays. (A) Schematic representation of myc-tagged ankrdl constructs carrying various configurations of introns 6-8 retention. Exons (E) are denoted with grey boxes and introns (i) with solid black horizontal lines. (B) -Western blot (WB) detection of cell-free (IVTT) expressed ankrd1 constructs with anti-myc (left panel) or anti-ANKRD1 (right panel) antibodies. Expressed constructs: ankrd1 (lane 1), ankrd1-i8 (lane 2), ankrd1-i7 (lane 3), and ankrd1-i6,7 (lane 4). Lane 5-IVTT control. MW values are indicated $(\mathrm{kDa})$. (C) Lysates of COS-7 cells transfected with myc-tagged ankrdl constructs were electrophoresed and immunoblotted with anti-myc (left panels) or anti-ANKRD1 (right panels) antibodies. LV - extract from LV of newborn piglets. The results from duplicate protein loading are presented. VT - vector only transfected cells. Both variant-specific $(a, b)$ and alternative $\left(a^{\prime}, b^{\prime}\right)$ isoforms generated due to splicing-out of the intron 7 or introns 6 and 7 from ankrd1-i7 and ankrd1-i6,7, respectively, were detected by anti-ANKRD1 antibodies. (D) Summary of ankrd1-i7 and ankrd1-i6,7 expression patterns in transfected COS-7 cells. a, b - translation of intron-bearing ankrd 1-i7 and ankrd1-i6,7 constructs resulted in correct myc-sequence read-through. $\mathrm{a}^{\prime}, \mathrm{b}^{\prime}-$ the removal of the entire intron 7 from a part of ankrd1-i7 or ankrd1-i6,7 (via splicing in COS-7 cells) produced a frame shift (FS) in the open reading frame within the $5^{\prime}$ region of the exon 8 that resulted in aberrant $m y c$-sequence read-through (white oval). See text for further details.

\subsection{SDS-PAGE and Western blotting}

Tissue/cell samples were homogenized and solubilized in standard $2 \times$ Laemmli buffer supplemented with complete protease inhibitor cocktail (Roche) as previously described (Torrado et al., 2006). Total protein lysates were subjected to SDS-PAGE (Mini-Protean-III, Bio-Rad), stained with Coomassie or blotted onto PVDF-membranes (Hybond-P, Amersham Biosciences), and probed with rabbit polyclonal antibodies against porcine ANKRD1 (Torrado et al., 2004) or mouse monoclonal anti-myc or anti-FLAG antibodies (Sigma). Molecular weight (MW) standards (MARK-12 and SeeBlue Plus2 from Invitrogen) were included on each gel. Equivalence of protein loading was confirmed by Amido-Black staining of blots before (blot-replicas) and after immunodetection. Blocking, washing, incubation with diluted primary and secondary HRP- 
conjugated antibodies (Sigma), and visualization of immunodecorated bands by the Super-Signal West Pico chemiluminescent substrate (Pierce Biotechnology) was carried out as described (Torrado et al., 2006). Substitution of the primary antibodies with anti-ANKRD1 antibodies neutralized by recombinant pig ANKRD1 was included in negative controls.

\subsection{Statistics}

Results are expressed as mean \pm SEM. Statistical significance was evaluated by Student's $t$ test. Statistical analyses were performed with SPSS 13 software. A value of $p \leq 0.05$ was considered statistically significant.

\subsection{Accession numbers}

The nucleotide sequence of the pig ankrd1-i8, ankrd1-i7,8 and ankrd1-i6,7,8 mRNA has been deposited in GenBank (http://www.ncbi.nlm.nih.gov/Genbank) under the accession numbers FJ475066, FJ475067 and FJ475068, respectively.

\section{Results}

\subsection{Differential display reveals intron 8-containing ankrd1 transcripts in the piglet heart}

The neonatal pig heart, which is characterized by distinct L-R patterns in ventricle growth and hypertrophy, represents a conventional model for the study of L-R molecular specification of early-postnatal myocardium in response to physiological pressure/volume overload stress (Torrado et al., 2004).

In order to screen for region-predominant mRNAs which are differentially regulated in the LV versus RV myocardium of newborn piglets, PCR differential display (RT-PCR-DD) was employed. This approach identified the differentially expressed transcripts (bands) whose relative levels in the LV are two- to four-fold higher as compared to the RV.

The five bands represented up-regulated genes in the LV (band DD36, DD155, DD159, DD160 and DD161; see Fig. 1A-C) were re-amplified, cloned and sequenced. BLAST similarity searches revealed a complete sequence homology of the DD155-, DD160- and DD161-band (Fig. $1 \mathrm{~B}, \mathrm{C}$ ) with the exon 8-9 sequence of the pig ankrdl transcript (Fig. 1D). Size difference $(\approx 100 \mathrm{bp})$ between the DD160- and DD161-fragment was observed, although the same primer pair was used for the amplification (primers A23-H04; Fig. 1C). The apparent reason for the truncation of the DD161 cDNA is a string of As located $100 \mathrm{bp}$ upstream its canonic poly(A) tail that led to $\mathrm{H} 04$ priming. In general, these results were consistent with LV-predominant distribution of the intronless ankrdl mRNA in ventricular myocardium of newborn piglets (Torrado et al., 2004).

The other two LV-predominant fragments (i.e., the DD36- and DD159-band; see Fig. 1A, C), amplified by different primer sets, did not show BLAST sequence homology to any known fullsized mRNA in the data base, but was found to be completely identical to the genomic sequence localized to the intron 8 of the pig ankrdl gene (Fig. 1D), as well as, to several pig EST sequences (Supplementary fig. 1). In addition, the longer cDNA product, representing the DD159-band, contained a short sequence that had a perfect nucleotide match with the 3 '-terminal region of exon 8 of the pig ankrdl (see Fig. 1D). Although each of these cDNA sequences was similar to the intron 8, they were not overlapping. RT-PCR, using a forward primer in the DD159 exon 8/intron 8 boundary and a reversed primer in the DD36, detected PCR products, each included both DD159 and DD36 sequences intervened by an additional $160 \mathrm{bp}$ of the ankrdl intron 8 sequence (data not shown). 
Collectively, the RT-PCR-DD results strongly suggested that both intronless and intronretaining ankrdl mRNAs are co-expressed and co-enriched in the LV myocardium of newborn piglets.

\subsection{Distinct intron 8-bearing ankrdl transcripts are detected in piglet heart}

As our RT-PCR-DD screen identified only partial DD36 and DD159 sequences localized to intron 8 of pig ankrdl, we set out to determine the nature of the intron 8-contained ankrdl transcripts. An overall 3'-RACE analysis of the DD36 (forward primer 182) and DD159 (forward primer 183) revealed the presence of intron 8 and exon 9 complete sequences, indicating that these RT-PCR-DD products belong to the ankrdl transcript(s), retaining the intron 8 (see Fig. 1D). However, no 5'-RACE PCR products were obtained using a reverse primer complementary to the forward primer 182 .

To overcome this problem, we used RT-PCR examination assays with primers designed to amplify between exon 1, 3 or 5 and intron 8 of the porcine ankrdl gene. Each primer pair gave rise to three differently sized PCR products with piglet LV cDNA (Fig. 1E). At least 6 plasmid clones were sequenced from each PCR product generated by each primer set. Sequence analysis of the cloned PCR products revealed that each primer set did generate identical overlapping (exons), but divergent in the 3' direction (intron-retained) sequences (Fig. 1F). Overall, RT-PCR analysis with the primer sets mapping across different exons and intron 8 revealed the presence of three ankrdl splice variants generated due to retention of: (1) intron 8 (i.e., ankrdl-i8), (2) introns 7 and 8 (i.e., ankrd1-i7,8), and (3) introns 6, 7 and 8 (i.e., ankrd1-i6,7,8). The ratio of RT-PCR products (see Fig. 1E) suggested a relatively lower expression of ankrd1-i6,7,8 as compared to ankrd1-i7,8 and ankrd1-i8 transcripts. These results document the natural occurrence of polyadenylated intronretaining ankrdl transcripts by RT-PCR, primed with oligo(dT), of total RNA from the LV myocardium of newborn piglets.

Fig. 1G shows schematic diagrams of the intronless ankrdl and its alternatively spliced variants. The ankrdl-i8 variant has a termination codon (TC) within the retained intron 8 sequence at position 81 . This splice variant would be expected to produce a protein truncated shortly after exon 8 with 26 additional amino acid residues from the $5^{\prime}$ region of intron-8. In the ankrd1-i7,8 variant, the retention of intron 7 produces a frame shift in the open reading frame which creates a downstream TC within the exon 8 sequence. The predicted protein product would have an intron 7 string but would lack a part of exon 8 , as well as, intron 8 and exon 9 sequences. The same feature seems to be probable for the ankrd1-i6,7,8 isoform which, in spite of intron 6 retention, would have a TC in exon 8 due to the retention of intron 7. Of note, the retention of intron 6 itself would not result in either frame shift or premature TC (PTC) in this variant. The ankrd1-i8, ankrd1-i7,8 and ankrd1-i6,7,8 putatively code for a 309, 305 and 339 amino acid protein with the deduced apparent MW value of $35.1,34.2$ and $37.7 \mathrm{kDa}$, respectively. These deduced values are comparable to that of pig intronless ANKRD1 (36.1 kDa). (see Supplementary fig. 2).

Thus, the results of structure analysis of three spliced variants of ankrdl identified in the LV myocardium of newborn piglets led us to predict that these transcripts, if effectively translated, would produce proteins with modified C-terminal segments.

\subsection{Intron-retaining ankrdl transcripts effectively translated into proteins in both cell-free and cell-based expression assays}

To probe whether the intron-retaining ankrdl transcripts are functionally intact and can be translated into protein, four myc-tagged constructions, each included the predicted coding sequence (Fig. 2A), were designed, in vitro translated and analyzed by SDS-PAGE followed by Western blot. For Western blot detection, a commercial mouse monoclonal anti-myc antibody and our lab-derived polyclonal antibodies generated in rabbits against $\mathrm{N}$-terminal segment of porcine ANKRD1 (Torrado et al., 2004) were used. Four distinct bands of the expected size for intronless ankrdl (44 kDa), ankrdl-i8 (44 kDa), ankrdl-i7,8 (43 kDa) and ankrd1-i6,7,8 (44 kDa) were observed on the blots developed by both antibodies used (Fig. 2B). The similar size of the putative 
proteins would probably make them undistinguishable from each other, as well as, from normally sized ANKRD1 protein in the heart tissue.

To assay the ability of the cDNA constructs to drive protein expression in mammalian cells, we transiently transfected COS-7 cells with the same myc-tagged versions of porcine ankrdl constructs (see Fig. 2A) and probed cell lysates by Western blotting with anti-myc and antiANKRD1 antibodies (Fig. 2C). Anti-myc detection revealed the expression of all ankrdl variantspecific products, each migrating in SDS-PAGE as one band of apparent molecular weight (MW) of $44 \mathrm{kDa}$ (Fig. 2C, left panel). The same protein products were also detected by anti-ANKRD1 antibodies. Moreover, the use of anti-ANKRD1 antibodies allowed the detection of alternative protein isoforms generated due to splicing-out of intron 7 or introns 6 and 7 from a part of ankrd1$i 7$ and ankrd1-i6,7 transcripts, respectively (Fig. 2C, right panel, lanes 8-11, arrows). Anti-myc detection did not reveal the expression of these alternative protein products because the removal of the entire intron 7 from both ankrd1-i7 and ankrdl-i6,7 (via splicing in COS-7 cells) produced, as predicted, a frame shift in the open reading frame within the $5^{\prime}$ region of exon 8 which, in turn, resulted in aberrant $m y c$-sequence read-through.

Overall, the data could be interpreted as evidence that alternative splicing of the ankrdl gene might result in expression of novel protein variants in the heart. However, intron-containing transcripts are frequently retained in the nucleus and targeted for degradation, preventing protein expression.

To test whether the ankrdl intron-containing transcripts are exported to the cytoplasm, we analyzed their expression in the RNA cytoplasmic fraction as compared with that in total LV-RNA from 6-day-old piglets. Each RT-PCR experiment was performed twice from separate cytoplasmic and total RNA isolations. As shown in Fig. 3, RT-PCR analysis revealed the presence of introncontaining ankrdl transcripts in both cytoplasmic and total RNA pools of LV-cardiomyocytes. The level of intron-containing transcripts in the RNA cytoplasmic fraction was 2-3-fold lower than that in the total RNA pool. Of note, the intronless ankrdl mRNA displayed a nearly identical relative proportion. The possibility of nuclear contamination of the cytoplasmic RNA preparation was excluded by testing for U6 small nuclear RNA (Mansilla et al., 2005). Although these results suggested that each ankrdl intron-retaining transcript may be translated into predicted protein, we could not detect discrete intron-retaining ankrdl isoforms, excepting a normally sized ANKRD1, on the LV-derived Western blots developed by our anti-ANKRD1 antibodies (data not shown). This could be explained by the low abundance of ankrdl intron-retaining variants, their rapid turnover in cardiac tissues or their MW size similarity to mature ANKRD1. 


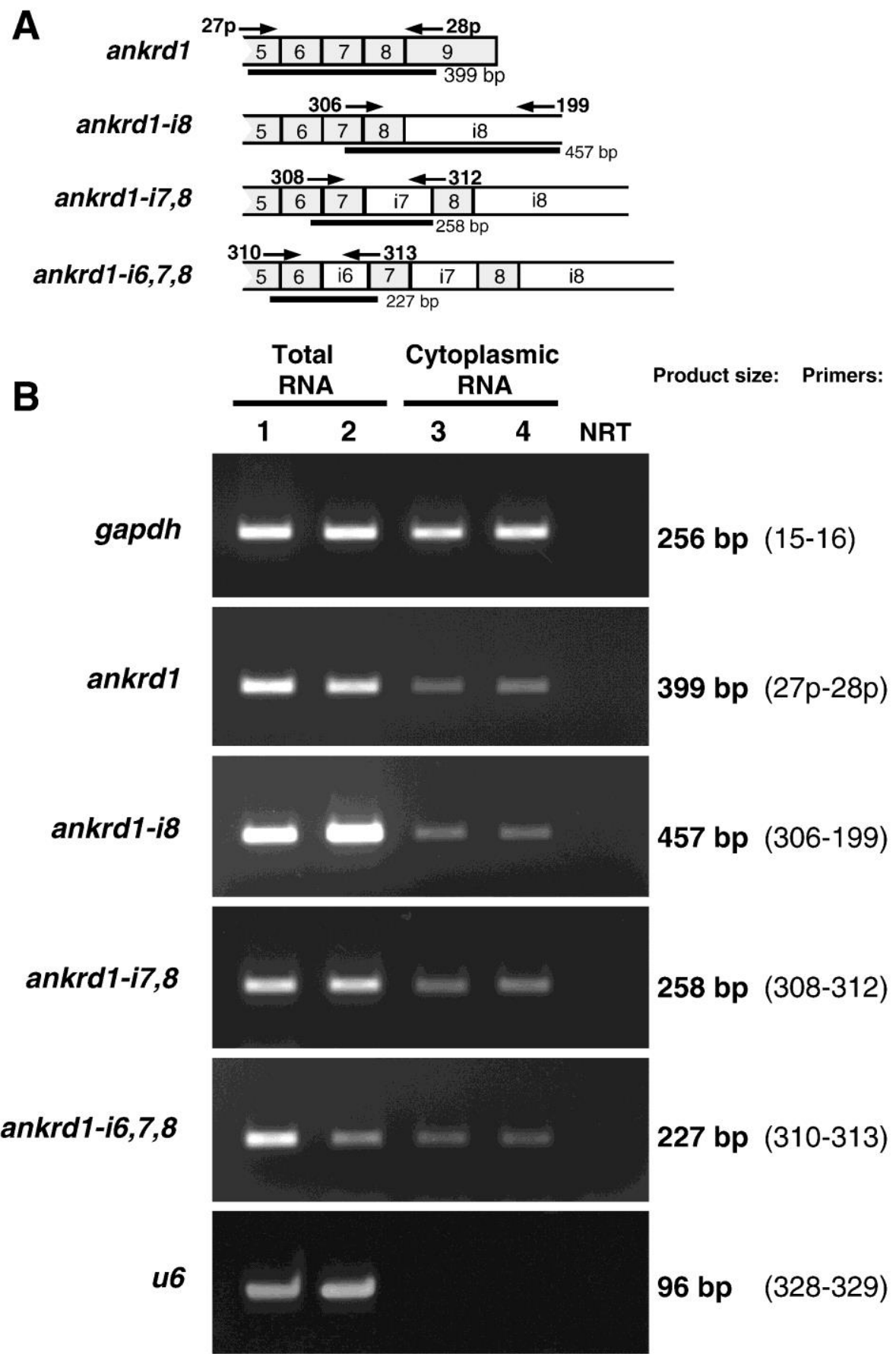

Fig. 3. Intron-containing ankrdl mRNAs are present in the cytoplasm of piglet cardiomyocytes. (A) Schematic representation of the pig intronless and intron-retaining ankrdl sequences used for primer design. Exons and introns are denoted with grey and white boxes, respectively. The approximate location of the primers for downstream RT-PCR analysis is shown (for primer sequences see Supplementary table 1). The expected size of the corresponding RCR products is shown in black lines. (B) Expression of intronless and intron-retaining ankrdl variants as revealed by RT-PCR of total and cytoplasmic RNA from piglet LV-derived cardiomyocytes, using the indicated set of primers. Gapdh amplification was carried out as an input RNA control for the RT-PCR. U6 small nuclear RNA amplification was carried out as a nuclear contamination control. Reactions were run in duplicate. PCR products were subcloned and sequenced to confirm that they corresponded to intron-retained ankrdl transcripts. 
In neonatal piglets, cardiac expression of normally sized ankrdl mRNA and protein is characterized by a shrinking asymmetric L-R distribution in both atrial and ventricular myocardium (Torrado et al., 2004, 2006). This led us to test whether expression of intron-retaining ankrdl variants are similarly regulated across cardiac chambers in newborn piglets. The analysis was performed by qPCR using the indicated set of forward-reverse primer pairs, each specific for selective amplification of pig ankrdl transcripts retaining intron 8, 7 or 6 (Fig. 4A). As expected, expression of the mature ankrd1 mRNA was enhanced 10 fold in the LV versus RV being also 1.6 fold higher in the left atrium (LA) as compared to the right atrium (RA). The intron-retaining ankrdl variants showed very similar patterns of expression in newborn pig heart. Only in the case of ankrd1-i8, the L-R expression differences, especially between LV and RV, were less prominent (Fig. 4B-F). 


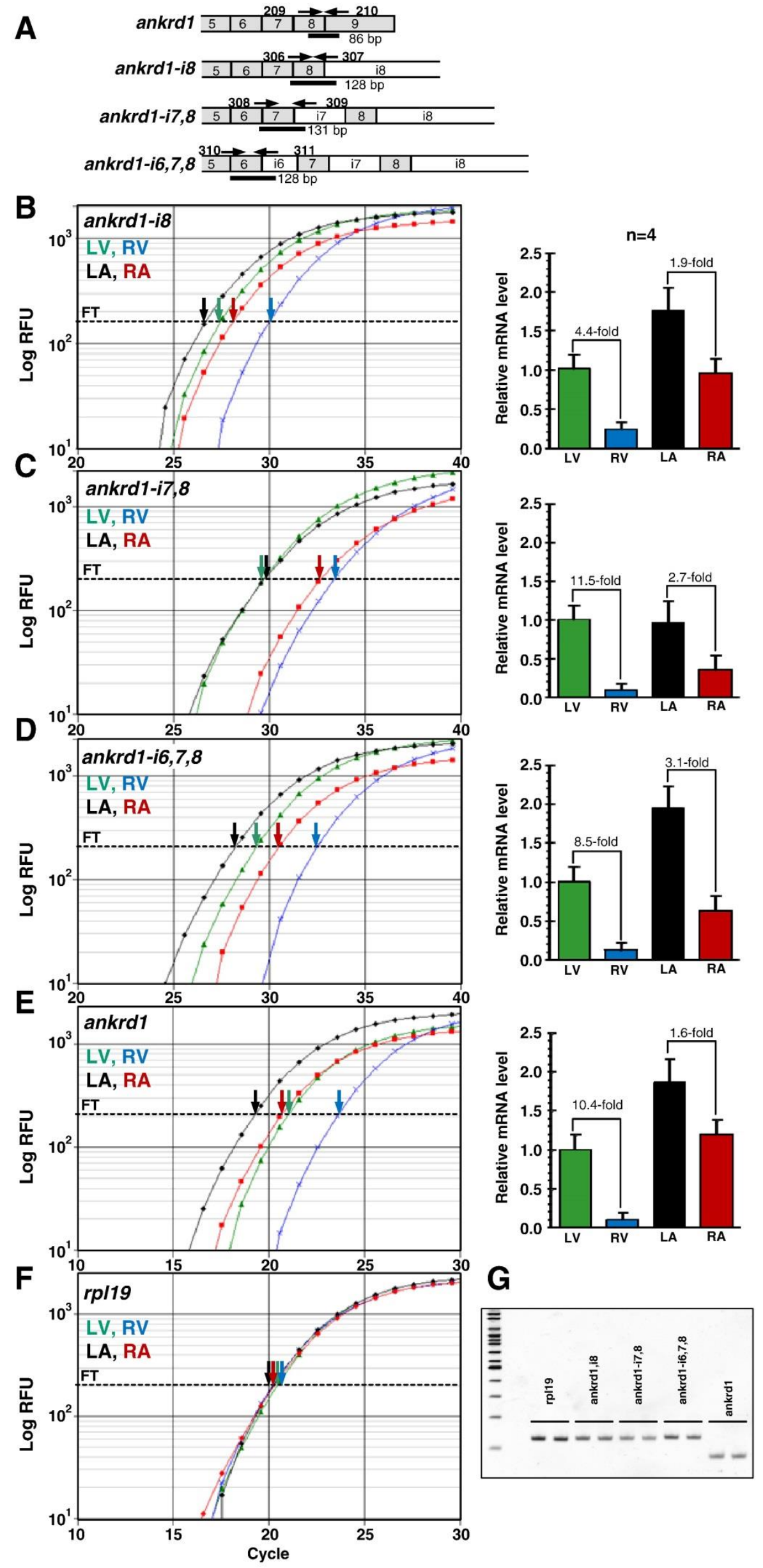


Fig. 4. Left-predominant expression of intron-retaining ankrdl transcripts in newborn piglet heart. (A) Schematic representation of the pig intronless and intron-retaining ankrdl sequences used for primer design. Exons and introns are denoted with grey and white boxes, respectively. The approximate location of the primers for downstream qPCR analysis is shown (for primer sequences see Supplementary table 1). (B-E) Representative qPCR amplification plots of intronless and intron-retaining ankrd1 mRNA levels in LV (green), RV (blue), LA (black), and RA (red). (F) internal rpl19 standard levels. Arrows - threshold cycle (CT). FT - fluorescent threshold. RFU-relative fluorescent units. (G) Each primer pair yielded a single band with the expected size on $8 \%$ PAAG post-stained with SYBR Green I. On the left, DNA size standards (GeneRuler DNA ladder mix; Fermentas) are shown.

The data suggest that there could be a chamber-dependent co-regulation (a positive regulation) of expression of intronless and intron-retaining ankrdl transcripts in neonatal pig heart.

\subsection{Intron-retaining ankrdl transcripts are markedly up-regulated in porcine model of heart failure}

Ankrdl has been identified as a gene that is upregulated in ventricular myocardium in both animal models and patients at HF secondary to various cardiac stresses (Mikhailov and Torrado, 2008). Utilizing our model of DHF-like syndrome in neonatal piglets (Torrado et al., 2006), we have carried out accurate quantification of the relative amounts of each ankrdl splice form in LV myocardium of control (i.e., PBS-injected) and experimental (i.e., Dox-injected) piglets (Fig. 5). Expression of intronless ankrdl transcript was coincidently enhanced 1.8-fold in the control versus failing myocardium. Similarly, the ankrdl intron-retaining transcripts were up-regulated in diseased myocardium, but each to a greater extent than that of the intronless ankrdl mRNA.

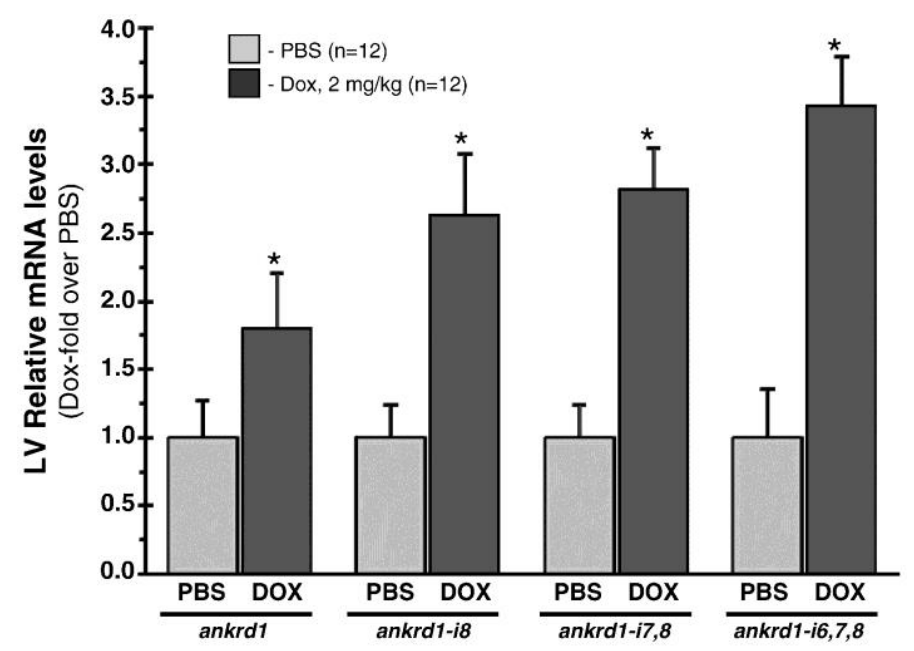

Fig. 5. Intron-retaining ankrdl variants are co-upregulated with the main transcript in failing piglet myocardium. qPCR analysis of intronless and intron-retaining ankrdl mRNA levels in the LV myocardium of Dox- versus PBS-injected piglets, using a primer set as indicated in Fig. 4. $p \leq 0.05$, for each transcript, Dox versus PBS.

The data provide evidence that experimental HF results in markedly enhanced expression of not only the intronless (Torrado et al., 2004, 2006), but also the intron-retained ankrdl mRNA species in failing myocardium, suggesting that ANKRD1 may positively regulate expression of its own intron-containing RNAs in response to cardiac stress. 
3.6. In vivo forced expression of intronless ankrdl leads to up-regulation of intron-retaining ankrdl transcripts in piglet myocardium

Given a positive co-expression pattern of the ankrdl mRNAs in normal and diseased piglet heart, we examined whether a forced expression of recombinant intronless ankrdl in LV myocardium could have an influence on the expression of endogenous intron-retaining ankrdl variants.

Using the delivery protocol developed by this team (Torrado et al., 2008), naked plasmids encoding porcine intronless ankrdl construction (8 animals) or empty vector (4 animals) were injected into target sites of the LV free wall (FW) of 6-day-old neonatal piglets (Fig. 6A). All ankrdl-transfected LVFWs harvested on day 2 post-delivery demonstrated transgene expression detectable by RT-PCR (Fig. 6B) and Western blot (Fig. 6D). In transfected LVFWs (region 2 and 6 from 8 ankrdl-transfected piglets), the amount of the endogenous intronless ankrdl mRNA, measured by qPCR assay, did not change significantly, whereas the expression of ankrdl-retaining variants was markedly up-regulated (Fig. 6C). It is important to note that a histological examination did not reveal inflammation in the LVFW target regions from ankrdl-delivered piglets. In all ankrdl-transfected animals, ventricular systolic and diastolic pressure values were not altered as compared to those in piglets intramyocardially injected with empty vector. At macroscopic examination, transfected animals had apparently normal heart morphology 2 and 7 days post-delivery as compared with age-matched controls (data not shown). 
A

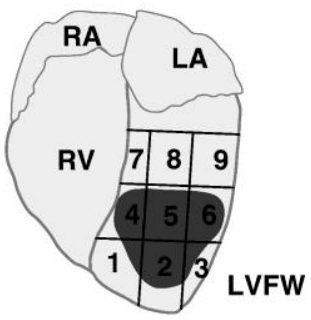

B

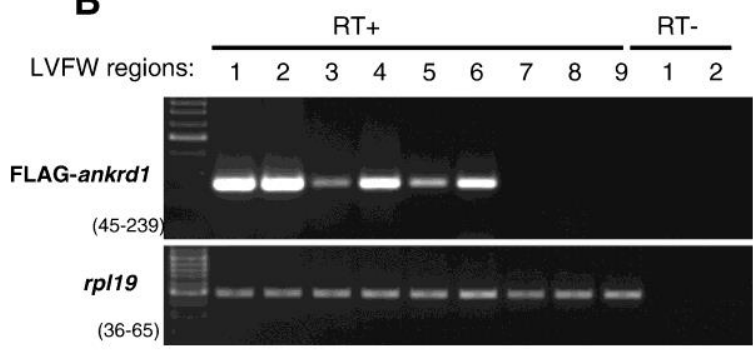

C

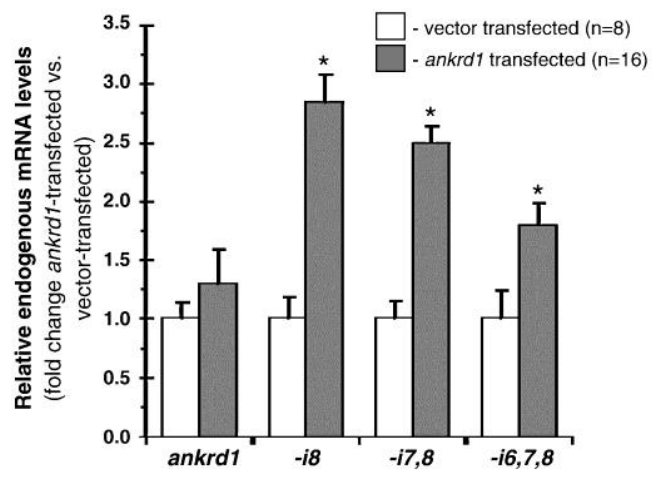

D
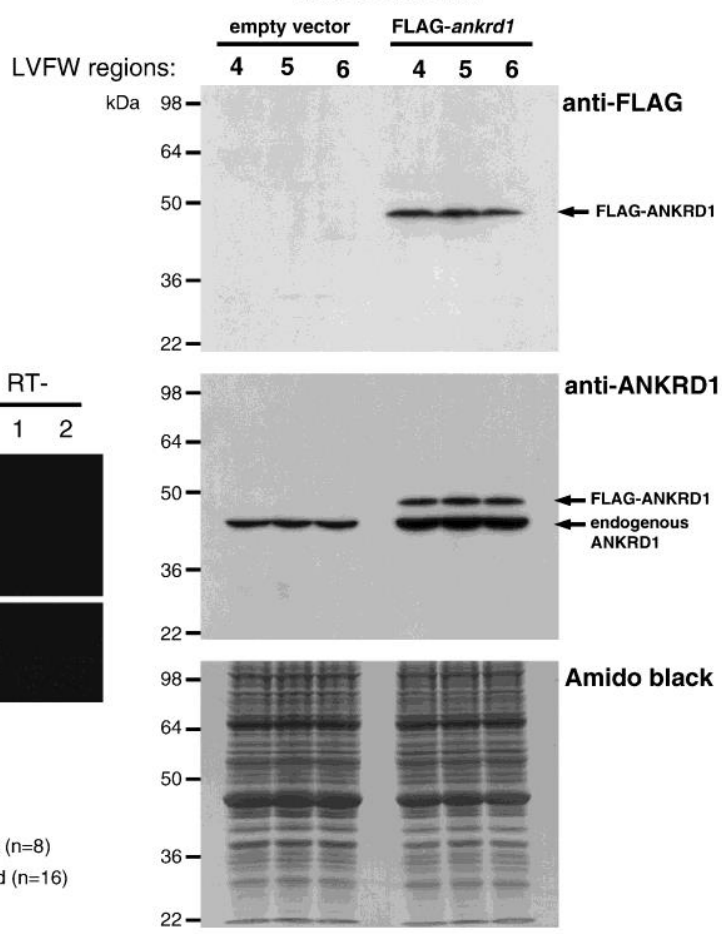

E

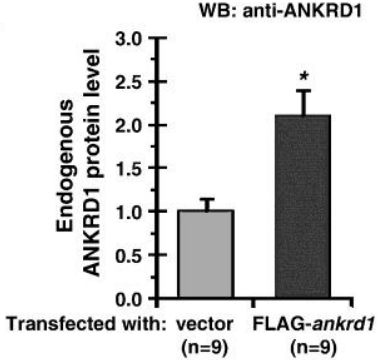

Fig. 6. In vivo forced expression of recombinant intronless ankrdl leads to up-regulation of endogenous intron-retaining ankrd1 transcripts in transfected piglet myocardium. (A) Schematic representation of ankrd1 transfected LVFW (dark grey, injection positions) which was dissected into nine fragments (1-9) 2 days after delivery. (B) Representative semiquantitative RT-PCR analysis of FLAG-tagged ankrdl transcript levels in nine LVFW fragments (after normalization of the cDNA templates to rpl19 expression). RT-: non-RT control. On the left-DNA size standards (GeneRuler DNA ladder mix; Fermentas). Primers are shown in brackets. A discriminating primer 239 is derived from the FLAG vector sequence (see Supplementary table 1). (C) Relative mRNA levels estimated by qPCR for endogenous intronless and intronretaining ankrdl transcripts in LVFW fragments 2 and 6 from ankrdl-transfected $(n=8)$ versus empty vector-transfected $(n=4)$ piglets. In total, 16 ankrd1- and 8 vector-delivered LVFW segments were processed. A primer set as indicated in Fig. 4 was used for amplification of intron-retaining ankrdl transcripts. The endogenous intronless ankrdl transcript was selectively amplified using a forward 327 primer and reverse primer 326 located in the ankrd1 3'-UTR (see Supplementary table 1). $\quad p \leq 0.05$, for each transcript, ankrd1-transfected versus vector transfected. (D) Western blot replicas of total protein extracted from zones 4, 5 and 6 of LVFWs injected with empty vector (left half of membranes) or FLAG-tagged ankrd1 (right half of membranes) were probed with anti-FLAG and anti-ANKRD1 antibodies or stained with Amido black (control of protein loading). (E) Relative levels estimated by Western blot for endogenous ANKRD1 in LVFWs transfected with empty vector or FLAG-tagged ankrd1. kDa-Protein MW standards. $p \leq 0.05$, for endogenous ANKRD1 (ankrd1transfected versus vector-transfected).

Having found significant up-regulation of intron-retaining ankrdl variants after ankrdl-vector transfection of LV myocardium, we compared the endogenous ANKRD1 protein level to that following vector only delivery. Our Western blot analysis provided evidence that intramyocardial delivery of an intronless ankrdl expression vector resulted in an approximately 2-fold increase of endogenous ANKRD1 protein levels in the target regions as compared to those transfected with empty vector (Fig. 6E). 
Overall, these results indicated that forced expression of intronless ankrdl transcript can result in up-regulation of its own intron-containing RNAs which, in turn, is associated with enrichment of endogenous protein products in transfected myocardium.

\subsection{Orthologues of porcine intron-retaining ankrdl variants are detected in human heart}

Because our results in piglet heart suggested that expression of intron-retaining ankrdl variants can be chamber-dependent and positively co-regulated with expression of the normally sized transcript (see Fig. 4), we asked whether such gene expression patterns also occurred in human postnatal myocardium. To examine this possibility, we first surveyed the presence of orthologues of the porcine intron-retaining ankrdl variants in human myocardium. In fact, orthologues of porcine ankrdl-i8 and ankrdl-i7,8 variants were readily detectable by our RT-PCR assay in human ventricular myocardium (Fig. 7A, B, D). The attempts, however, failed to demonstrate the existence of the ankrdl-i6,7,8 orthologue in human cardiac samples. In infant human heart, the intronless ankrdl transcript was more abundant in the LV as compared to the RV. Overall, this expression pattern was comparable to those of ankrdl-i8 and ankrdl-i7,8 mRNAs which showed a trend towards a small 1.5-fold enrichment in the LV over the RV (Fig. 7B-D). 
A

A ankrd1-i7,8
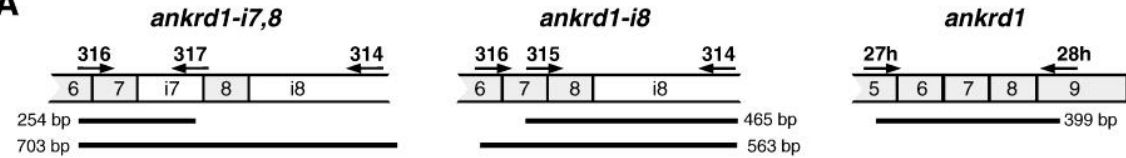

B

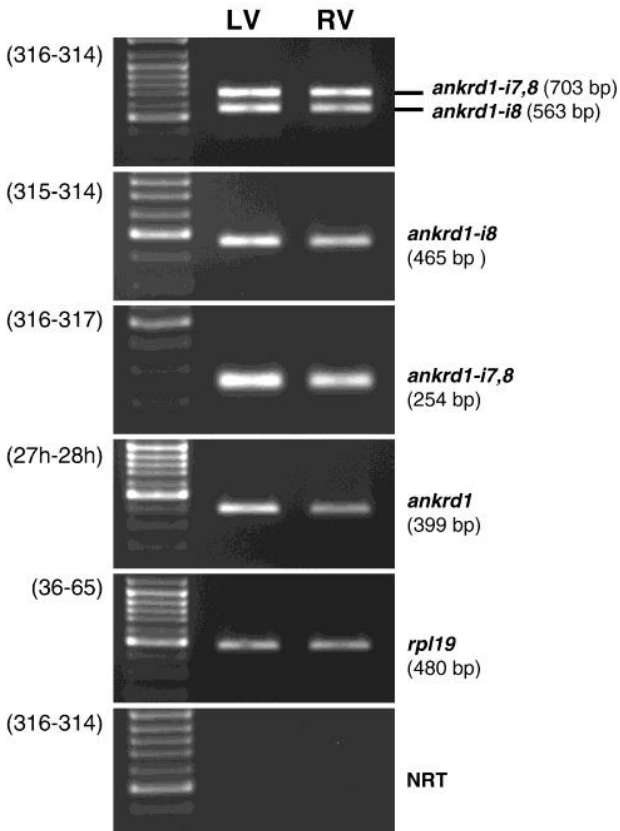

C
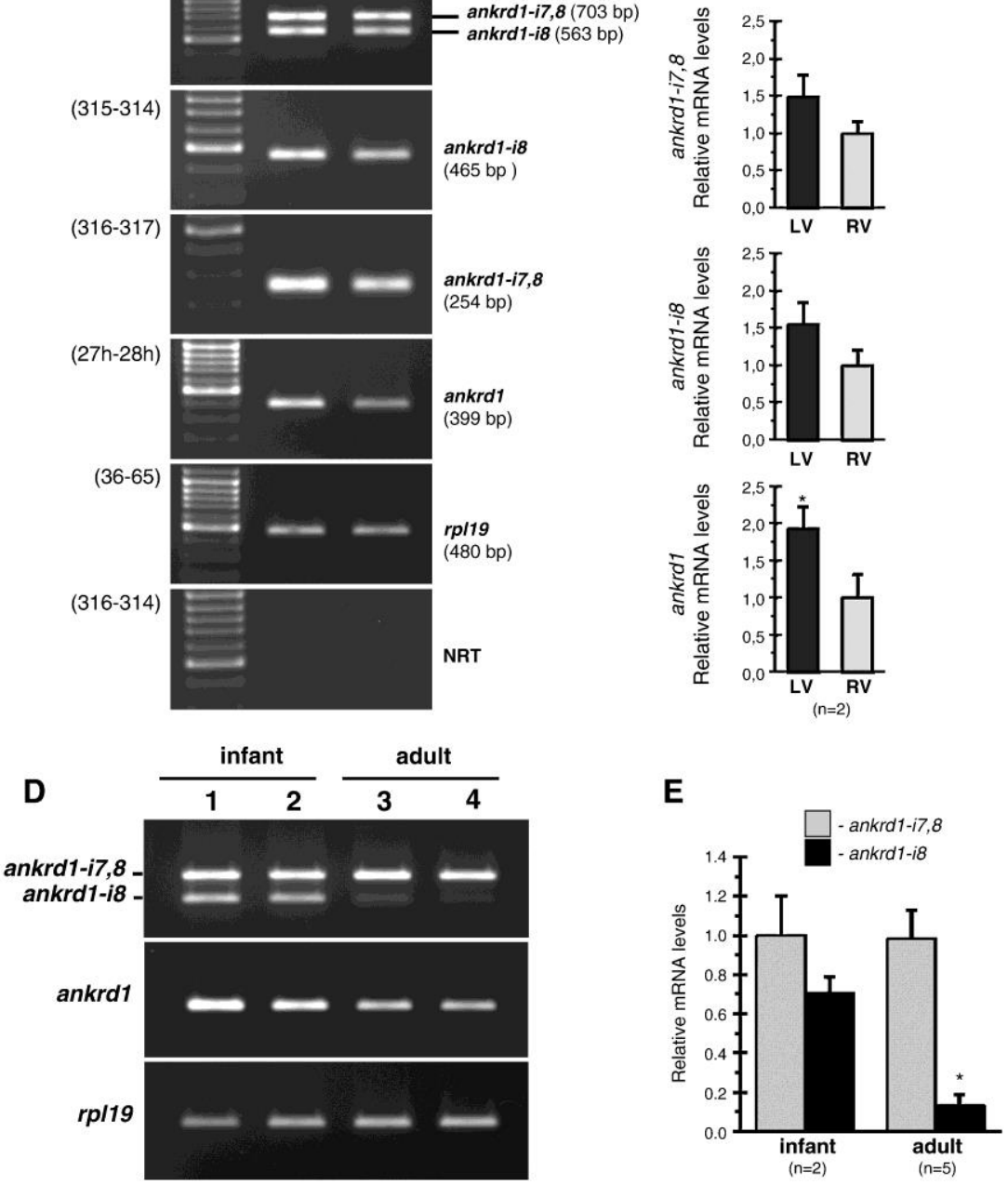

Fig. 7. Intron-retaining ankrd1 transcripts are detected in infant and adult human heart. (A) Schematic representation of the human intronless and intron-retaining ankrdl sequences used for primer design. Representative (B) and average relative (C) mRNA levels estimated by semiquantitative RT-PCR for ankrd1 splice and $r p l-19$ transcripts in LV/RV samples from 8-week-old infant. On the left-GeneRuler DNA ladder mix (Fermentas). Representative (D) and average relative (E) mRNA levels estimated by semiquantitative RT-PCR for ankrdl splice and rpl-19 transcripts in LV myocardium from infant and adult donors. Lane 1-8-week-old; lane 2-1-year-old; lane 3-42-year-old; lane 4-43-year-old. $p \leq 0.05$.

We also compared ankrdl splicing in RNA samples from infant and adult human LV myocardium to assess regulation during human postnatal development. Infant cardiac tissues express the ankrd1-i8 variant at higher levels in comparison to the adult heart suggesting that its expression is down-regulated with aging. The expression levels of the intronless ankrdl transcript were also down-regulated in adult as compared to those in infant LV samples, but the differences were not statistically significant. The amount of the ankrdl-i7,8 did not differ appreciably between infant and adult human LV samples. 


\section{Discussion}

To this date, only single normally sized ankrdl transcript had been reported in mammals, but, interestingly, two ankrdl transcripts had been detected in the chicken muscle tissue by Northern blot hybridizations (Yang et al., 2005). The present results show the occurrence of alternative splicing by intron retention events in the pig and human ankrdl gene. In pig heart, ankrdl is expressed as four alternatively spliced transcripts, three of which have non-excised introns: ankrdl-contained introns 6, 7 and 8, ankrdl-contained introns 7 and 8, and ankrdl only retained intron 8 . These new splice ankrdl variants were unexpectedly identified during our RT-PCR-DD analysis of the transcripts differentially expressed in the LV versus RV myocardium of newborn piglets. In human heart, two orthologues of porcine intron-retaining ankrdl variants (i.e., ankrdl$i 8$ and ankrdl-i7,8) are detected. Recently, an as yet un-characterized intron-contained ankrdl transcript was found to be expressed and up-regulated in neonatal rat cardiomyocytes in response to endothelin stimulation (Cullingford et al., 2008). Our in silico analysis revealed that the identified human and pig ankrdl intron-retaining sequences are conserved in a limited number of higher mammals and primates (60-70\% of sequence homology), demonstrating insignificant (lower mammals) or no homology to other vertebrate counterparts.

Often, retention of internal introns restricts the export of these mRNAs and makes them the targets for degradation by the nonsense-mediated mRNA decay (NMD) pathway, particularly if they contain premature TC (Blencowe, 2006; Lareau et al., 2007). We have employed a variety of complimentary approaches to demonstrate that the identified intron-retaining ankrdl transcripts are functionally intact and efficiently translated into protein in vitro (see Fig. 2B). Moreover, we have provided evidence that the ankrdl intron-retaining transcripts are exported to the cytoplasm in cardiomyocytes in vivo. The equal proportions of intronless and intron-retaining ankrdl transcripts between the total and cytoplasmic RNA pool from piglet cardiomyocytes (see Fig. 3) suggest that nuclear transcripts are of similar composition to those in the cytoplasm, and therefore not necessarily committed to NMD-mediated degradation. Collectively, the results indicate that each of the identified ankrdl intron-retaining transcripts can be translated into protein in cardiac tissues.

A major question is the extent to which these alternatively spliced ankrdl transcripts could be functionally significant. Our results address this question using a combination of experimental approaches that allowed us to monitor the cardiac levels of these splice variants in different in vivo settings. Using the rna22 algorithm (Miranda et al., 2006), we identified putative binding sites for several cardiac miRNAs (Thum et al., 2007) in the human ankrdl intron 8 sequence suggesting that the expression of intron-8-retained and intronless ankrdl transcripts might be differentially regulated in the heart. However, in both pig and human neonatal heart the expression of intronless and ankrdl-i8 variants was found to be similarly co-regulated in a chamber-dependent manner (see Figs. 4 and 7) influenced, at least in part, by different types of biomechanical stress in the left as compared to the right myocardium (Torrado et al., 2004).

It is generally recognized that the presence of introns in a primary transcript can promote more abundant gene expression (Nott et al., 2003). Intron-retaining ankrdl transcripts were found to be markedly up-regulated, with the main transcript, in ventricular myocardium in porcine model of DHF (see Fig. 5). Because protein is produced more rapidly from pre-existing mRNAs than from transcription of a gene, it is conceivable that intron-retaining ankrdl transcripts enable cardiac cells to respond quickly to stress by making ANKRD1 immediately available for tissue remodeling. The findings, stemming from our gene delivery experiments, are well in line with such a view. Forced myocardial expression of recombinant intronless ankrdl resulted in upregulation of endogenous intron-retaining ankrdl variants (but not of the endogenous main transcript), which, in turn, was associated with enrichment of endogenous ANKRD1 protein products in transfected piglet myocardium (see Fig. 6D, E). Future studies, beyond the scope of the present work, will be needed in order to detail the mechanism and functional significance of co-regulated expression of intronless and intron-retaining ankrdl transcripts in myocardium.

Conflicting hypotheses regarding the role of alternative splicing-NMD coupling in regulation of gene expression exist (Lareau et al., 2007). As previously suggested, NMD activated by alternative splicing events can represent a mechanism by which expression of a given gene could be down-regulated in a tissue-restricted manner (Alonso, 2005). Other observations indicate, 
however, that the majority of PTC-containing transcripts generated by alternative splicing are detected at uniformly low abundance levels across mammalian tissues, independently of the NMD action (Pan et al., 2006). Our data contribute, to some extent, to the current knowledge of this issue. Both the intronless and intron-retaining ankrdl transcripts are constitutively co-expressed in the neonatal pig heart and similarly up-regulated in porcine failing myocardium, suggesting the mRNA population resulting from the ankrdl gene is not homogeneous in cardiomyocytes, but rather is present in a number of transcripts proportionate to its splicing probability. Moreover, in all experimental settings analyzed, the higher level of intron-retaining ankrdl transcripts was always associated with a higher ANKRD1 protein content in piglet myocardium.

In mice, a total ankrdl knockout resulted in a complete lack of phenotype (Barash et al., 2007), suggesting that ANKRD1 is not crucial for regulation of cardiac gene expression in vivo, as it has been proposed in the past (Zolk et al., 2002, 2003). However, ankrdl augmented expression can represent an adaptive response of the myocardium to stress both during development and various heart insults (Mikhailov, Torrado, 2008). Expression of several ankyrin repeat proteins was found to be associated with cell survival (Miles et al., 2005). In this regard, forced expression of normally sized ankrdl in rat embryonic cardiomyocytes (Han et al., 2005) and human microvascular endothelial cells (Samaras et al., 2007) increases their resistance to Dox-induced stress/apoptosis which correlates with a decrease in caspase-3 activity. It is not clear whether intron-retaining ankrdl variants, up-regulated in myocardium of piglets exposed to Dox, have a similar functional phenotype. Our preliminary results indicate that forced expression of intronless and splice ankrdl variants in COS-7 cells (see Fig. 2C) results in lower levels of caspase-3 activation as compared to those of empty vector-transfected cells (data not shown).

As predicted, translation of the characterized intron-retaining ankrdl transcripts would produce proteins with modified C-termini (see Supplementary fig. 2). Studies of ANKRD1 protein interactions have focused on the use of the normally sized protein, or on its $\mathrm{N}$ - or C-terminal domain in isolation (Zou et al., 1997; Torrado et al., 2004, 2005; Witt et al., 2005; Hayashi et al., 2008). The present work suggests that ANKRD1 isoforms that lack a part of their C-termini can be present in cardiomyocytes and will require further detailed analysis. The ANKRD1-i8 isoform would retain all conserved ankyrin repeat motifs which were found to be important for interactions of ANKRD1 with titin (Miller et al., 2003) and cardiac calsequestrin (Torrado et al., 2005), while both ANKRD1-i7,8 and ANKRD1-i6,7,8 would lack the 4th ankyrin repeat (see Supplementary fig. 2).

Lastly, it is worth to note that in quantitative RT-PCR analysis the use of the primers annealing to the first six exons of the ankrdl gene would generate a common PCR product amplified from both intronless and intron-retaining ankrdl transcripts. Also, the question of cardiac expression of ANKRD1 needs to be addressed because commercial and lab-derived antibodies used, for example, in immunohistochemical studies, could not differentiate between the intronless and intron-retaining ANKRD1 isoforms.

In sum, the results presented here demonstrate that ANKRD1 can exist in multiple isoforms within cardiomyocytes in pigs and humans. Intron-retaining ankrdl transcripts were found to be markedly up-regulated in porcine failing myocardium and, therefore, the relevance of the ankrdl gene to the pathogenesis of HF in humans (Mikhailov and Torrado, 2008) would require analysis of its splicing pattern in cardiac muscle samples from patients with advanced heart insufficiency.

\section{Acknowledgments}

This work was supported by grants (SAF2004-01462 and SAF2008-00337) from the Spanish Ministry of Science and Innovation and partially by a grant (08CSA008161PR) from the Autonomic Government of Galicia. HPLC-purified primers for RT-PCR-DD were a generous gift from Dr. Max Rothschild (Iowa State University, USA). We thank Drs. Marisa Crespo, Javier Muñiz and Constancio Medrano (University Hospital Centre of La Coruña, Spain) for their help in sampling and characterization of human heart tissues, and Dr. Stanislav Tomarev (NIH, Bethesda, USA) for his support of cell-based assays. 


\section{References}

Aihara Y., et al.Cardiac ankyrin repeat protein is a novel marker of cardiac hypertrophy: role of M-CAT element within the promoter. Hypertension, 36 (2000), pp. 48-53

Alonso C.R.Nonsense-mediated RNA decay: a molecular system micromanaging individual gene activities and suppressing genomic noise. Bioessays, 27 (2005), pp. 463-466

Bakay M., Zhao P., Chen J., Hoffman E.P.A web-accessible complete transcriptome of normal human and DMD muscle. Neuromuscul. Disord. 12 Suppl, 1 (2002), pp. S125-141

Baumeister A., Arber S., Caroni P.Accumulation of muscle ankyrin repeat protein transcript reveals local activation of primary myotube endcompartments during muscle morphogenesis. J. Cell Biol., 139 (1997), pp. 1231-1242

Barash I.A., Bang M.L., Mathew L., Greaser M.L., Chen J., Lieber R.L.Structural and regulatory roles of muscle ankyrin repeat protein family in skeletal muscle. Am. J. Physiol. Cell Physiol., 293 (2007), pp. C218-C227

Blais A., Tsikitis M., Acosta-Alvear D., Sharan R., Kluger Y., Dynlacht B.D.An initial blueprint for myogenic differentiation. Genes Dev., 19 (2005), pp. 553-569

Blencowe B.J.Alternative splicing: new insights from global analyses. Cell, 126 (2006), pp. $37-47$

Boengler K., Pipp F., Fernandez B., Ziegelhoeffer T., Schaper W., Deindl E.Arteriogenesis is associated with an induction of the cardiac ankyrin repeat protein (carp). Cardiovasc. Res., 59 (2003), pp. 573-581

Bowman T.V., et al.Differential mRNA processing in hematopoietic stem cells. Stem Cells, 24 (2006), pp. 662-670

Casey W.M., Brodie T., Yoon L., Ni H., Jordan H.L., Cariello N.F.Correlation analysis of gene expression and clinical chemistry to identify biomarkers of skeletal myopathy in mice treated with PPAR agonist GW610742X. Biomarkers, 13 (2008), pp. 364-376

Cinquetti R., et al.Transcriptional deregulation and a missense mutation define ANKRD1 as a candidate gene for total anomalous pulmonary venous return. Hum. Mutat., 29 (2008), pp. $468-474$

Cullingford T.E., et al.Temporal regulation of expression of immediate early and second phase transcripts by endothelin-1 in cardiomyocytes. Genome Biol., 9 (2008), p. R32

Chu W., Burns D.K., Swerlick R.A., Presky D.H.Identification and characterization of a novel cytokine-inducible nuclear protein from human endothelial cells. J. Biol. Chem., 270 (1995), pp. 10236-10245

De Jaco A., Camp S., Taylor P.Influence of the 5 ' intron in the control of acetylcholinesterase gene expression during myogenesis. Chem. Biol. Interact., 157-158 (2005), pp. 372-373

Dong X.J., Guan H.P., Zhang Q.D., Yerle M., Liu B.Mapping of porcine ANKRD1, ANKRD2, ANKRD23, VGLL2 and VGLL4 using somatic cell and radiation hybrid panels. Anim. Genet., 38 (2007), pp. 424-425

Fernandes J.M., MacKenzie M.G., Kinghorn J.R., Johnston I.A.FoxK1 splice variants show developmental stage-specific plasticity of expression with temperature in the tiger pufferfish. J. Exp. Biol., 210 (2007), pp. 3461-3472

Granzier H.L., Labeit S.The giant protein titin: a major player in myocardial mechanics, signaling, and disease. Circ. Res., 94 (2004), pp. 284-295

Han X.J., Chae J.K., Lee M.J., You K.R., Lee B.H., Kim D.G.Involvement of GADD153 and cardiac ankyrin repeat protein in hypoxia-induced apoptosis of H9c2 cells. J. Biol. Chem., 280 (2005), pp. 23122-23129

Hayashi C.Multiple molecular interactions implicate connectin/titin N2A region as a modulating scaffold for p94/calpain 3 activity in skeletal muscle. J. Biol. Chem., 283 (2008), pp. 14801-14814

Hiroi Y., et al.Tbx5 associates with $\mathrm{Nkx} 2-5$ and synergistically promotes cardiomyocyte differentiation. Nat. Genet., 28 (2001), pp. 276-280

Jeyaseelan R., et al.A novel cardiac-restricted target for doxorubicin. CARP, a nuclear modulator of gene expression in cardiac progenitor cells and cardiomyocytes. J. Biol. Chem., 272 (1997), pp. 22800-22808

Kanai H., et al.Transforming growth factor-beta/Smads signaling induces transcription of the cell type-restricted ankyrin repeat protein CARP gene through CAGA motif in vascular smooth muscle cells. Circ. Res., 88 (2001), pp. 30-36

Kokame K., Kato H., Miyata T.Nonradioactive differential display cloning of genes induced by homocysteine in vascular endothelial cells. Methods, 16 (1998), pp. 434-443

Korb M., Ke Y., Johnson L.F.Stimulation of gene expression by introns: conversion of an inhibitory intron to a stimulatory intron by alteration of the splice donor sequence. Nucleic Acids. Res., 21 (1993), pp. 5901-5908

Kuo H., Chen J., Ruiz-Lozano P., Zou Y., Nemer M., Chien K.R.Control of segmental expression of the cardiac-restricted ankyrin repeat protein gene by distinct regulatory pathways in murine cardiogenesis. Development, 126 (1999), pp. 4223-4234 
Lareau L.F., Brooks A.N., Soergel D.A., Meng Q., Brenner S.E.The coupling of alternative splicing and nonsense-mediated mRNA decay. Adv. Exp. Med. Biol., 623 (2007), pp. 190-211

Le Hir H., Nott A., Moore M.J.How introns influence and enhance eukaryotic gene expression. Trends Biochem. Sci., 28 (2003), pp. 215-220

Mansilla A., et al.Developmental regulation of a proinsulin messenger RNA generated by intron retention. EMBO Rep., 6 (2005), pp. 1182-1187

Mikhailov A.T., Torrado M.The enigmatic role of the ankyrin repeat domain 1 gene in heart development and disease. Int. J. Dev. Biol., 52 (2008), pp. 811-821

Miles M.C., et al.Molecular and functional characterization of a novel splice variant of ANKHD1 that lacks the KH domain and its role in cell survival and apoptosis. FEBS J., 272 (2005), pp. 4091-4102

Miller M.K., et al.The muscle ankyrin repeat proteins: CARP, ankrd2/Arpp and DARP as a family of titin filament-based stress response molecules. J. Mol. Biol., 333 (2003), pp. 951-964

Miller M.K., Granzier H., Ehler E., Gregorio C.C.The sensitive giant: the role of titin-based stretch sensing complexes in the heart. Trends Cell. Biol., 14 (2004), pp. 119-126

Miranda K.C., et al.A pattern-based method for the identification of microRNA binding sites and their corresponding heteroduplexes. Cell, 126 (2006), pp. 1203-1217

Nakada C., et al.Cardiac ankyrin repeat protein is preferentially induced in atrophic myofibers of congenital myopathy and spinal muscular atrophy. Pathol. Int., 53 (2003), pp. 653-658

Nott A., Meislin S.H., Moore M.J.A quantitative analysis of intron effects on mammalian gene expression. RNA, 9 (2003), pp. 607-617

Nurmi J.T., Puolakkainen P.A., Rautonen N.E.Intron 1 retaining cyclooxygenase 1 splice variant is induced by osmotic stress in human intestinal epithelial cells. Prostaglandins Leukot. Essent. Fat. Acids, 73 (2005), pp. 343-350

Osinska H.E., Lemanski L.F.Immunofluorescent studies on Z-line-associated protein in cultured cardiomyocytes from neonatal hamsters. Cell Tissue Res., 271 (1993), pp. 59-67

Pan Q., et al.Quantitative microarray profiling provides evidence against widespread coupling of alternative splicing with nonsense-mediated mRNA decay to control gene expression. Genes Dev., 20 (2006), pp. 153-158

Rajeevan M.S., Ranamukhaarachchi D.G., Vernon S.D., Unger E.R.Use of real-time quantitative PCR to validate the results of cDNA array and differential display PCR technologies. Methods, 25 (2001), pp. 443-451

Samaras S.E., Shi Y., Davidson J.M.Novel actions of cardiac ankyrin repeat protein. Int. Congr. Ser., 1302 (2007), pp. 53-64.

Shi Y., et al.CARP, a cardiac ankyrin repeat protein, is up-regulated during wound healing and induces angiogenesis in experimental granulation tissue. Am. J. Pathol., 166 (2005), pp. 303-312

Stam F.J., et al.Identification of candidate transcriptional modulators involved in successful regeneration after nerve injury. Eur. J. Neurosci., 25 (2007), pp. 3629-3637

Thum T., et al.MicroRNAs in the human heart: a clue to fetal gene reprogramming in heart failure. Circulation, 116 (2007), pp. 258-267

Torrado M., Lopez E., Centeno A., Medrano C., Castro-Beiras A., Mikhailov A.T.Myocardin mRNA is augmented in the failing myocardium: expression profiling in the porcine model and human dilated cardiomyopathy. J. Mol. Med., 81 (2003), pp. 566-577

Torrado M., Lopez E., Centeno A., Castro-Beiras A., Mikhailov A.T.Left-right asymmetric ventricular expression of CARP in the piglet heart: regional response to experimental heart failure. Eur. J. Heart Fail., 6 (2004), pp. 161-172

Torrado M., Nespereira B., Lopez E., Centeno A., Castro-Beiras A., Mikhailov A.T.ANKRD1 specifically binds CASQ2 in heart extracts and both proteins are co-enriched in piglet cardiac Purkinje cells. J. Mol. Cell. Cardiol., 38 (2005), pp. 353-365

Torrado M., Nespereira B., Bouzamayor Y., Centeno A., Lopez E., Mikhailov A.T.Differential atrial versus ventricular ANKRD1 gene expression is oppositely regulated at diastolic heart failure. FEBS Lett., 580 (2006), pp. 4182-4187

Torrado M., Centeno C., López E., Mikhailov A.T.In-vivo forced expression of myocardin in ventricular myocardium transiently impairs systolic performance in early neonatal pig heart. Int. J. Dev. Biol., 52 (2008), 10.1387/ijdb.072366mt

Wang H.F., Feng L., Niu D.K.Relationship between mRNA stability and intron presence. Biochem. Biophys. Res. Commun., 354 (2007), pp. 203-208

Witt S.H., Labeit D., Granzier H., Labeit S., Witt C.C.Dimerization of the cardiac ankyrin protein CARP: implications for MARP titin-based signaling. J. Muscle Res. Cell Motil., 26 (2005), pp. 401-408

Witt C.C., Witt S.H., Lerche S., Labeit D., Back W., Labeit S.Cooperative control of striated muscle mass and metabolism by MuRF1 and MuRF2. Embo J., 27 (2008), pp. 350-360 
Yang W., Zhang Y., Ma G., Zhao X., Chen Y., Zhu D.Identification of gene expression modifications in myostatin-stimulated myoblasts. Biochem. Biophys. Res. Commun., 326 (2005), pp. 660-666

Yoshida H., Nadanaka S., Sato R., Mori K.XBP1 is critical to protect cells from endoplasmic reticulum stress: evidence from Site-2 protease-deficient Chinese hamster ovary cells. Cell Struct. Funct., 31 (2006), pp. 117-125

Zhao C., Hamilton T.Introns regulate the rate of unstable mRNA decay. J. Biol. Chem., 282 (2007), pp. 20230-20237

Zolk O., et al.Cardiac ankyrin repeat protein, a negative regulator of cardiac gene expression, is augmented in human heart failure. Biochem. Biophys. Res. Commun., 293 (2002), pp. $1377-1382$

Zolk O., Marx M., Jackel E., El-Armouche A., Eschenhagen T.Beta-adrenergic stimulation induces cardiac ankyrin repeat protein expression: involvement of protein kinase A and calmodulin-dependent kinase. Cardiovasc. Res., 59 (2003), pp. 563-572

Zou Y., Evans S., Chen J., Kuo H.C., Harvey R.P., Chien K.R.CARP, a cardiac ankyrin repeat protein, is downstream in the Nkx2-5 homeobox gene pathway. Development, 124 (1997), pp. 793-804 